D.O.I.: $10.3895 /$ gi.v10i3.1708

\title{
AUDITORIA DA NR 17 NO POSTO DE TRABALHO DOS OPERADORES DE CAIXA DE UM BANCO
}

\section{NR 17 ASSESSMENT IN A WORKING STATION OF A BANK CASH OPERATORS}

\author{
Fábio Xavier de Oliveira ${ }^{1}$; Marcelo Augusto Oliveira da Justa ${ }^{2}$ \\ ${ }^{1}$ Universidade Federal do Amazonas - UFAM -Manaus/AM - Brasil \\ fabio_xav@hotmail.com \\ ${ }^{2}$ Universidade Federal do Amazonas - UFAM - Manaus/AM - Brasil \\ marcelo.justa@bol.com.br
}

\begin{abstract}
Resumo
Com o intuito de minimizar o descaso com as condições de trabalho e melhorar a qualidade de vida dos colaboradores da maioria das empresas do setor industrial foi criada uma norma regulamentadora sobre análises ergonômicas, a NR17. Dentre os principais objetivos estão os seguintes: possibilitar o conforto ao indivíduo, prevenir acidentes, danos à saúde e colaborar com o aumento da produtividade, por meio da satisfação e conforto dos colaboradores envolvidos. No setor bancário, diante de várias reclamações e queixas dos funcionários sobre possiveis problemas ergonomicos no ambiente de trabalho dos operadores de caixa de um banco, viu-se a necessidade de realizar uma análise ergonômica do posto de trabalho, a fim de investigar possíveis irregularidades no setor com base na NR 17. Neste contexto, a pesquisa teve como objetivo realizar uma auditoria de todos os itens da NR 17 no setor dos caixas de um banco e mensurar sua adequação a referida norma. A metodologia utilizada foi de natureza bibliográfica, descritiva, de campo, quantitativa e estudo de caso, com observações "in loco", entrevistas informais $e$ acompanhamento diário das atividades. Após a conclusão da auditoria, foi constatado que 42,42\% dos itens avaliados não estão conforme a norma recomenda.
\end{abstract}

Palavras-chave: análise ergonômica; condições de trabalho; NR 17; conformidade.

\section{Introdução}

O bancário das organizações atuais sofre muito a influência das incessantes mudanças decorrentes da economia globalizada, em que as atividades e os negócios crescem cada vez mais. O cenário na era da informatização está baseado na produtividade, competitividade e qualidade, acima de tudo. Nesse contexto, os bancários, especialmente os operadores de caixa de banco são afetados pelos bens e males da era da globalização e da informação, e ainda das constantes modificações tecnológicas que acontecem na execução do trabalho, impactando significativamente no desenvolvimento das atividades. 
Mesmo diante de alta tecnologia agregada à atividade bancária, não foi dada a devida atenção para melhorias nas condições de trabalho. Em contrapartida, houve um aumento de pressão e ritmo de serviço, acompanhado de novas formas de controle e de organização do trabalho que exigem níveis maiores de responsabilidades dos trabalhadores.

Para acompanhar essas mudanças, faz-se necessário proporcionar aos funcionários, condições adequadas para execução de suas tarefas e atividades com conforto e segurança. Dessa forma, projetar o posto de trabalho e organizar o sistema de produção com boas condições ergonômicas são tarefas fundamentais. A análise ergonômica tem como principais objetivos possibilitar o conforto ao indivíduo, prevenir acidentes, danos à saúde e, conseqüentemente, colaborar com o aumento produtivo da empresa, por meio da satisfação e conforto dos colaboradores envolvidos.

Com o intuito de minimizar o descaso com as condições de trabalho e melhorar a qualidade de vida dos colaboradores da maioria das empresas do setor industrial foi criada uma norma regulamentadora sobre análises ergonômicas, a Norma Regulamentadora de Segurança e Saúde do Trabalhador - Ergonomia (NR 17), estabelecida pelo Ministério do Trabalho e Emprego por meio da portaria $\mathrm{n}^{\mathrm{o}} 3.751$ de 23 de novembro de 1990, e tem como objetivo estabelecer parâmetros que permitam a adaptação das condições de trabalho às características psicofísiológicas dos trabalhadores, de modo a proporcionar o máximo de conforto, segurança e desempenho eficiente (MTE, 2013).

A NR 17 prevê que as condições de trabalho incluem aspectos relacionados ao levantamento, transporte e descarga de materiais, ao mobiliário, aos equipamentos, às condições ambientais do posto de trabalho e à própria organização do trabalho. Diz também que para avaliar a adaptação das condições de trabalho às características psicofisiológicas dos trabalhadores, cabe ao empregador realizar a análise ergonômica do trabalho, devendo a mesma abordar, no mínimo, as condições de trabalho conforme estabelecido naquela norma (MTE, 2013).

Segundo Iida (2005, p. 159) afirma que "muitos produtos e postos de trabalho inadequados provocam tensões musculares, dores e fadiga", ou seja, a configuração dos produtos e postos de trabalho, muitas vezes, são responsáveis pelos desgastes humanos no trabalho. Também podem gerar prejuízo ao desempenho do trabalhador, contribuir com a incidência de absenteísmo nas empresas e riscos de distúrbios músculo-esqueléticos.

A importância da pesquisa se dá pela escassez de materiais relacionados ao tema proposto e ainda pelo grande número de afastamentos no setor bancário. Segundo dados da Folha de São Paulo, Peres (2009), o Ministério da Previdência Social gastou R\$ 981 milhões entre 2000 e 2005 para pagar auxílio-doença a 25,08 mil bancários afastados do trabalho por doenças causadas por esforços repetitivos. Cada um desses trabalhadores ficou, em média, um ano e meio afastado. Portanto, somando 14,9 milhões de dias sem trabalhar. 
A problemática das reclamações e queixas dos operadores de caixa de um banco, que alegavam sentir dores nas costas, pernas e membros superiores, em função de prováveis problemas ergonômicos no posto de trabalho, desencadeou o objetivo dessa pesquisa. Desta forma, pretende-se realizar a análise ergonômica do posto de trabalho dos operadores de caixa. Especificamente procurou-se fazer uma auditoria de todos itens da NR 17, a fim de verificar a adequação do posto de trabalho a referida norma.

Em relação aos resultados práticos, esta pesquisa procura apresentar a organização estudada para a necessidade de se adequar às exigências contidas na NR 17 - Ergonomia. Desta forma, oferecer condições de trabalho mais adequadas aos seus colaboradores e atendendo à legislação vigente. Também objetiva incentivar o interesse pelo assunto abordado, tanto da organização pesquisada, quanto dos acadêmicos interessados em desenvolver pesquisas nesta área.

A metodologia utilizada na pesquisa foi de natureza bibliográfica, por meio da consulta de livros, artigos científicos e dissertações para auxiliar e direcionar a análise ergonômica deste trabalho. Também descritiva com o objetivo de descrever as condições de trabalho de determinado grupo de trabalhadores. De campo, pois foi realizada no local onde ocorreram os fenômenos pesquisados. Quantitativa porque traduz em números, opiniões e informações que posteriormente serão classificadas e analisadas. Estudo de caso, pois realiza o estudo da pesquisa dentro de uma empresa para identificação da problemática.

\section{Fundamentos teóricos}

\subsection{Definições para ergonomia}

Segundo Vidal (2011) a ergonomia é uma ocupação de pessoas qualificadas para responder às demandas acerca da atividade de trabalho. O objetivo da ergonomia é adequar o trabalho ao homem, relacionando todas as interações que influenciam na realização do trabalho, como máquinas, equipamentos, métodos, ambiente, visando preservar a saúde do trabalhador, proporcionando segurança e produtividade.

A palavra ergonomia é derivada das palavras gregas ergon (trabalho) e nomos (regras). Trata-se de uma disciplina orientada para uma abordagem sistêmica de todos os aspectos da atividade humana (ABERGO, 2013).

De acordo com a ABERGO (2013) a ergonomia objetiva modificar sistemas de trabalho para adequar as atividades nele existentes às características, habilidades e limitações das pessoas com a finalidade de obter desempenho eficiente, confortável e seguro. A ergonomia é caracterizada em quatro tipos de acordo com a ocasião em que é realizada (WISNER, 1987 apud IIDA, 2005, p. 13): 
a) Ergonomia de concepção: ocorre quando a ergonomia contribui no início do projeto de produto, da máquina, ambiente ou sistema. Essa é a melhor situação, pois as alternativas podem ser amplamente examinadas, e se bem formulada a análise ergonômica, poderá ajudar para que não se obtenha problemas ergonômicos;

b) Ergonomia de correção: é aplicada em situações reais, onde já existe um problema, procurando-se a solução do mesmo. Muitas vezes a solução adotada não é completamente satisfatória, pois pode demandar elevado custo de implantação, logo se faz necessário buscar soluções que se adaptem à realidade e condições da organização;

c) Ergonomia de conscientização: procura capacitar os próprios trabalhadores para identificação e correção dos problemas cotidianos ou aqueles emergenciais. É importante capacitar os trabalhadores, pois nem sempre os problemas são completamente resolvidos na fase de concepção e na fase de correção;

d) Ergonomia de participação: tem como objetivo envolver o próprio usuário do sistema, na solução de problemas ergonômicos. O trabalhador participa da resolução do problema ergonômico, baseando-se na idéia que ele possua um conhecimento prático, cujos detalhes podem passar despercebidos ao analista ou projetista.

Ocorre que após o término da segunda guerra mundial, surgiu na Europa uma nova vertente da ergonomia ensejada pelas necessidades da reconstrução do parque industrial europeu destruído. A fábrica de automóveis da Renault, na França, foi a primeira a criar um laboratório industrial voltado para a ergonomia. Posteriormente, originou-se a escola francesa que tinha como questão própria: como desenvolver adequadamente postos de trabalho a partir de uma situação existente?

Segundo Másculo e Vidal (2011) A. Wisner formalizou a Análise Ergonômica do Trabalho (AET) que tem como partida uma solicitação feita por uma gerência ou dirigente acerca de um problema de produção, de saúde no trabalho, de desempenho de um produto ou eficácia organizacional, tais como:

a) Análise da demanda - esta etapa consiste em procurar entender a natureza e a dimensão dos problemas apresentados. É necessário haver um acordo entre todas as partes envolvidas (gerentes, trabalhadores, ergonomistas, supervisores) para que se possa delimitar o problema, definir prazos, custos para a resolução do problema;

b) Análise da tarefa - nessa fase o ergonomista irá analisar as diferenças entre o trabalho que é prescrito e o que realmente é realizado. Pode haver alguma discrepância por conta de máquinas desasjustadas, materiais irregulares e também porque nem todos trabalhadores seguem rigidamente o método descrito; 
c) Análise da atividade - refere-se ao comportamento do trabalhador na realização da tarefa, ou seja, são as ações que o trabalhador faz para alcançar os objetivos que lhe foram atribuídos. A atividade é influenciada por fatores internos e externos. Os fatores internos localizamse no próprio trabalhador e os fatores externos referem-se às condições em que a atividade é executada;

d) Formulação do diagnóstico - procura descobrir as causas que provocam o problema descrito na demanda. Podem ter vários fatores, relacionados ao trabalho e à empresa, que influenciam na atividade de trabalho;

e) Recomendações ergonômicas - refere-se às providências que deverão ser tomadas para resolver o problema diagnosticado. As recomendações devem ser bem especificadas e todas as etapas necessárias para a resolução do problema devem ser descritas. É necessário um plano de ação, indicando os responsáveis pelas ações, prazos, custos, etc.

\subsection{A norma regulamentadora NR 17}

A necessidade da criação da NR 17 se deu no ano de 1986 com o surgimento de vários casos de tenossivonite ocupacional entre digitadores. Diante de tal problemática, os diretores da área de saúde do Sindicato de Empregados em Empresa de Processamento de Dados no Estado de São Paulo (SIDPD) entraram em contato com a Delegacia Regional do Trabalho de São Paulo (DRT/SP) buscando soluções para a prevenção destas lesões. Desta forma, foi constituída uma equipe formada por médicos, representantes sindicais e engenheiros que, através de análises ergonômicas e fiscalizações, verificou as condições de trabalho e a influência destas sobre a saúde do colaborador, dando os primeiros passos na coleta de dados e identificação das causas das lesões (MTE, 2013).

A NR 17 possui diretrizes que orientam as organizações sobre os diversos aspectos do ambiente de trabalho e das atividades realizadas pelos funcionários, tais como: mobiliário adequado, realização de tarefas com maior segurança e sua distribuição durante o dia, iluminação, temperatura e ruídos. Após considerar todos os fatores ambientais, a organização deve realizar a AET que irá determinar quais serão as modificações e melhorias que devem ser executadas (SEFIT, 2013).

A atual NR 17 - Ergonomia, estabelecida pelo Ministério do Trabalho por meio da Portaria $\mathrm{n}^{\mathrm{o}}$ 3.751, define os parâmetros que permitem a adaptação das condições de trabalho às características psicofisiológicas dos trabalhadores, a fim de proporcionar o máximo de conforto, segurança e desempenho eficiente (MTE, 2013).

Antes da elaboração dessa norma, não havia normatização alguma em que o Ministério do Trabalho e Emprego pudesse se apoiar para obrigar as empresas a alterar a forma pela qual era 
organizada a produção. Portanto, a fiscalização das condições ergonômicas oferecidas pelas empresas ficava muito prejudicada e carente de embasamento legal.

Atualmente, as normas regulamentadoras expedidas pelo MTE são de observância obrigatória pelas empresas públicas e privadas e pelos órgãos públicos da administração direta e indireta, bem como pelos órgãos dos Poderes Legislativo, Executivo e Judiciário, que possuam empregados regidos pela Consolidação das Leis do Trabalho. Neste contexto, o objetivo da NR 17 é caracterizar a ergonomia como um importante instrumento para garantir a segurança e a saúde dos trabalhadores, bem como a produtividade das empresas (MTE, 2013).

A NR 17 representa uma evolução significativa na estruturação das condições dos postos de trabalho nas empresas do país. Antes de sua elaboração, as alterações na organização do trabalho eram de iniciativa exclusiva das empresas. Até então, a organização do trabalho era considerada intocável e passível de ser modificada apenas por iniciativa da empresa, muito embora os estudos comprovassem o papel decisivo desempenhado por ela na gênese de numerosos comprometimentos à saúde do trabalhador (MUNDO ERGONOMIA, 2013).

Atualmente, cabem ao empregador realizar a análise ergonômica dos postos de trabalho, considerando, no mínimo, as condições de trabalho conforme estabelecido pela NR 17. Portanto, deve-se considerar a análise ergonômica do trabalho como um processo construtivo e participativo para a resolução de um problema complexo, exigindo o conhecimento das tarefas, da atividade desenvolvida para realizá-las e das dificuldades enfrentadas para atingir o desempenho e a produtividade exigidos (MTE, 2013).

\section{A auditoria com base na NR17}

A pesquisa foi realizada no setor dos operadores de caixa de um banco, localizado na cidade de Manaus, no período de 02 de junho até 06 de setembro do ano de 2013, envolvendo 03 (três) colaboradores dessa função. Dessa forma, a pesquisa foi realizada com 100\% do universo, e pelo fato de ser uma pesquisa qualitativa tornou-se desnecessário a determinação da amostra.

A pesquisa foi feita através de observações “in loco”, com acompanhamento diário das atividades no setor, registrando os problemas com fotografias, vídeos e caderno de anotações. Foram ainda realizadas entrevistas informais com os colaboradores, a fim de avaliar e verificar possíveis reclamações e queixas que estivessem atrapalhando no desenvolvimento das atividades ou prejudicando a saúde.

Foram analisados todos os itens aplicáveis da NR 17 e confrontados com os dados coletados no ambiente de trabalho, a fim de identificar quais atividades e pontos do posto de trabalho não estavam de acordo com a referida norma. Os itens foram classificados em três categorias: conforme, não conforme e não aplicável. 
Foram analisados 16 itens aplicáveis da NR 17 que foram enumerados de requisito 1 a 16 . Contudo, existem itens da norma que se dividem em outros subitens em forma de alíneas. Por exemplo: o requisito 2, divide-se em alínea a, b e c. Para esses casos considerou-se cada alínea como sendo um item isolado para análise. Sendo assim, foram verificados um total de 45 itens da norma, sendo que 12 deles foram considerados não aplicáveis às atividades de caixa, restando o universo de 33 itens para análise da auditoria, classificados em conformes e não conformes.

Os itens 17.2.1.1; 17.2.1.2; 17.2.1.3; 17.2.2; 17.2.3; 17.2.4; 17.2.5; 17.2.6; 17.2.7 da NR 17, referem-se ao levantamento, transporte e descarga individual de materiais. Portanto, não se aplicam ao estudo de caso, pois as cargas levantadas e transportadas na atividade de caixa de banco são muito leves, ou quase nulas, não oferecendo perigo a saúde do trabalhador.

Verificou-se ainda que o item 17.3.2.1 não se aplica, pois os caixas não utilizam os pés para acionar pedais e outros comandos que influenciem no resultado e execução das atividades. Os itens 17.3.5 e 17.5.2, alínea c, também não se aplicam, pois o trabalho dos caixas é realizado na posição sentada. Trata-se de um ambiente de trabalho em sala fechada, portanto, não sendo necessário medir a velocidade do ar.

$\mathrm{Na}$ sequencia, apresenta-se a análise da auditoria com base nos requisitos da norma. Os itens e subitens a seguir, referem-se ao mobiliário dos postos de trabalho.

Requisito 1: Item 17.3.1. Sempre que o trabalho puder ser executado na posição sentada, o posto de trabalho deve ser planejado ou adaptado para esta posição. A análise identificou que este item está não conforme. O trabalho é realizado na posição sentada, porém existem mesas e assentos sem ajustes de altura, gerando a não conformidade, como mostra a Figura 1A e B.

Requisito 2: Item 17.3.2. Para trabalho manual sentado ou que tenha de ser feito em pé, as bancadas, mesas, escrivaninhas e os painéis devem proporcionar ao trabalhador condições de boa postura, visualização e operação e devem atender aos seguintes requisitos mínimos:

a) Ter altura e características da superfície de trabalho compatíveis com o tipo de atividade, com a distância requerida dos olhos ao campo de trabalho e com a altura do assento;

b) Ter área de trabalho de fácil alcance e visualização pelo trabalhador;

c) Ter características dimensionais que possibilitem posicionamento e movimentação adequados dos segmentos corporais.

Para a alínea A, a análise identificou este item como não conforme. A mesa está com altura acima do especificado, causando mal posicionamento dos braços, como mostra a Figura 1A. Também o assento com altura abaixo do especificado e sem ajuste, ocasionando mal posicionamento das pernas, conforme Figura 1B. O monitor também está em posicão elevada em 
relação ao campo de visão do trabalhador, isto é, acima do o ângulo visual desejado, e sem ajuste de inclinação com a horizontal, indicado na Figura 1C.

A análise identificou que a alínea B está conforme.

$\mathrm{A}$ análise identificou que a alínea $\mathrm{C}$ está não conforme. As mesas, assentos e monitores nào possuem regulagens de altura, dificultando a movimentacão adequada dos segmentos corporais, conforme indicado na Figura 1.

Figura 1 - Não conformidades

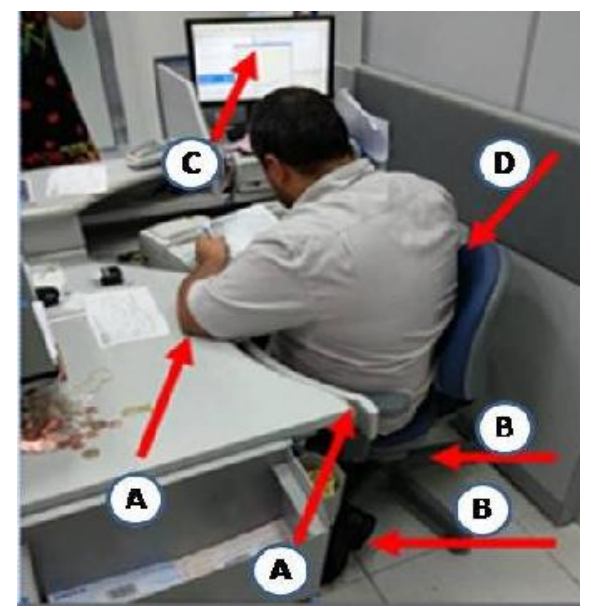

Fonte: Autoria própria (2013).
Figura 2 - Dimensões e posturas recomendadas

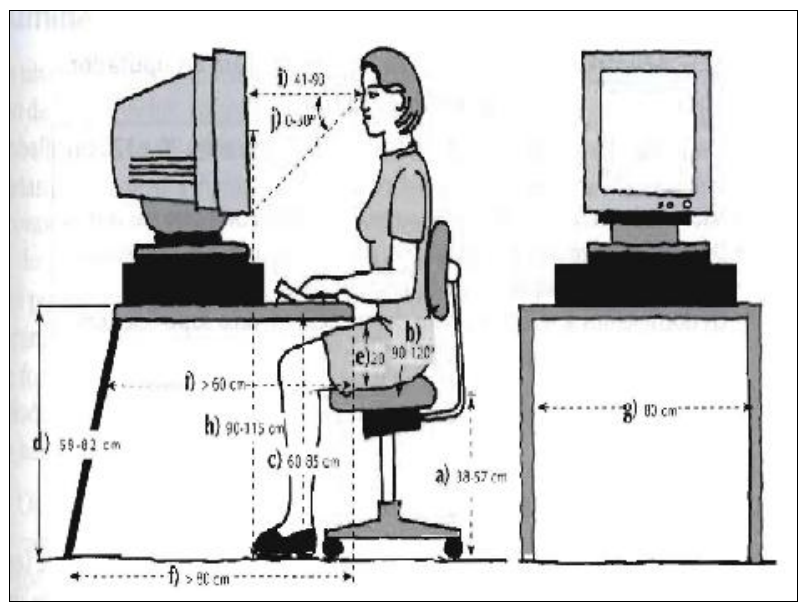

Fonte: Adaptado de Iida (2005, p.215)

A Figura 2 mostra a posição e dimensões recomendadas para o posto de trabalho com computadores, evidenciando as não conformidades encontradas.

Requisito 3: Item 17.3.3. Os assentos utilizados nos postos de trabalho devem atender aos seguintes requisitos mínimos de conforto:

a) Altura ajustável à estatura do trabalhador e à natureza da função exercida;

b) Características de pouca ou nenhuma conformação na base do assento;

c) Borda frontal arredondada;

d) Encosto com forma levemente adaptada ao corpo para proteção da região lombar.

A análise identificou que a alínea $\mathrm{A}$ está não conforme. $\mathrm{O}$ assento não possui ajuste de altura, prejudicando a posição das pernas do trabalhador. As mesmas ficam completamente fora do padrão, como apresentado na Figura 3. 
Figura 3 - Cadeira sem ajuste

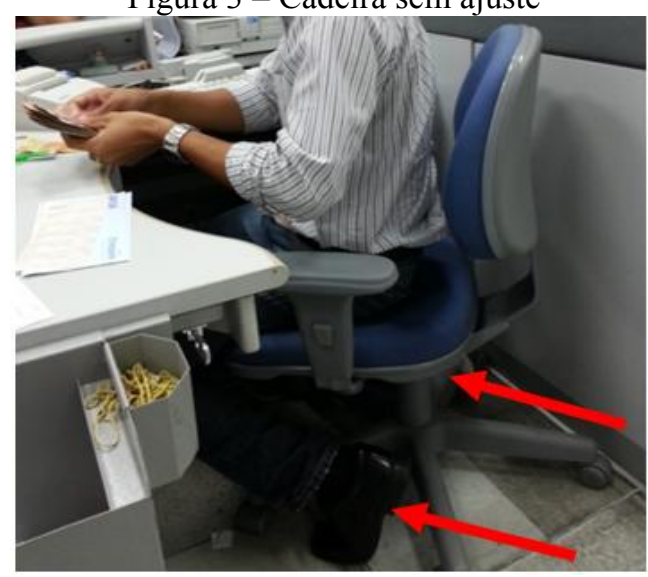

Fonte: Autoria própria (2013)

A análise identificou que as Alíneas B, C e D estão conforme.

Requisito 4: Item 17.3.4. Para as atividades em que os trabalhos devam ser realizados sentados, a partir da análise ergonômica do trabalho, poderá ser exigido suporte para os pés, que se adapte ao comprimento da perna do trabalhador.

A análise identificou que este item está não conforme, pois os postos de trabalho não possuem suporte para os pés, conforme Figura 4.

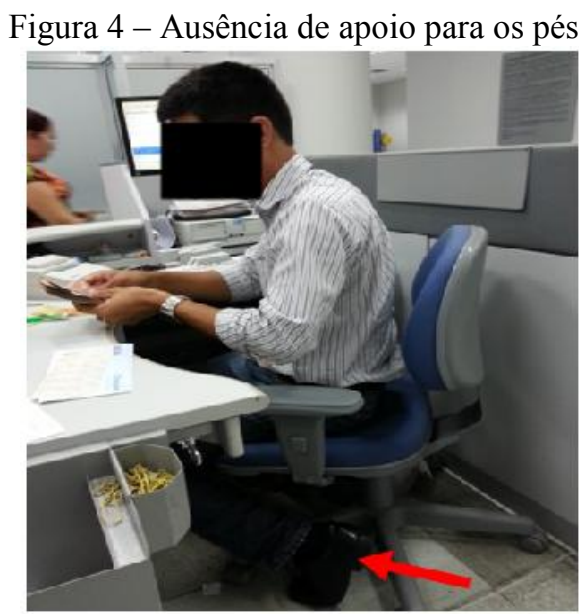

Fonte: Autoria própria (2013)
Figura 5 - Exemplos de apois para os pés
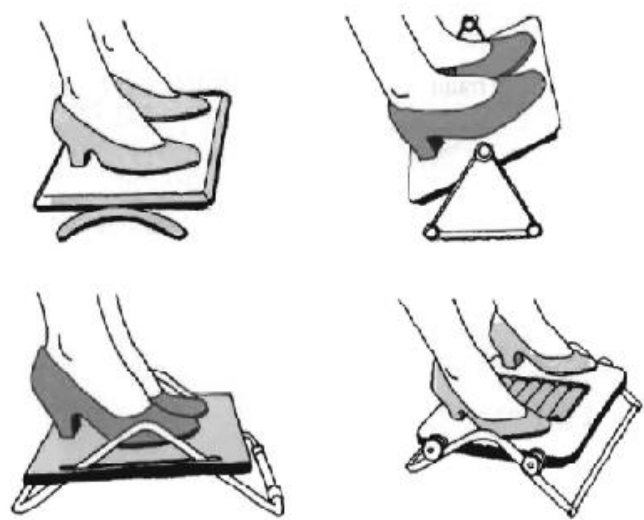

Fonte: Adaptado de Iida (2005, p.209)

A Figura 5 apresenta os tipos de apoio necessários para os pés. Os mesmo não foram identificados nos postos de trabalho, gerando a não conformidade.

Na sequencia, apresenta-se a análise da auditoria com base nos requisitos da norma. Agora, os itens a seguir referem-se aos equipamentos dos postos de trabalho.

Requisito 5: Item 17.4.1. Todos os equipamentos que compõem um posto de trabalho devem estar adequados às características psico-fisiológicas dos trabalhadores e à natureza do trabalho a ser executado. 
A análise identificou que este item está não conforme, pois nem todos os equipamentos do posto de trabalho estão adequados às necessidades dos trabalhadores, conforme mencionado nos itens 17.3.2 alínea A e C, 17.3.3 alínea A e 17.3.4, conforme mostrado na Figura 1.

Requisito 6: Item 17.4.2. Nas atividades que envolvam leitura de documentos para digitação, datilografia ou mecanografia:

a) Deve ser fornecido suporte adequado para documentos que possa ser ajustado proporcionando boa postura, visualização e operação, evitando movimentação freqüente do pescoço e fadiga visual;

b) Deve ser utilizado documento de fácil legibilidade sempre que possível, sendo vedada a utilização do papel brilhante, ou de qualquer outro tipo que provoque ofuscamento.

A análise identificou que a alínea A está não conforme, pois não existe suporte para leitura e digitação de documentos, conforme mostrado na Figura 1 e 6 . Verifica-se que o trabalhador está segurando nas mãos o documento e fazendo esforço para ler e efetuar a digitação.

A análise identificou que a alínea $B$ está Conforme, pois os documentos são legíveis e não provocam ofuscamento.

Requisito 7: Item 17.4.3. Os equipamentos utilizados no processamento eletrônico de dados com terminais de vídeo devem observar o seguinte:

a) Condições de mobilidade suficientes para permitir o ajuste da tela do equipamento à iluminação do ambiente, protegendo-a contra reflexos, e proporcionar corretos ângulos de visibilidade ao trabalhador;

b) O teclado deve ser independente e ter mobilidade, permitindo ao trabalhador ajustá-lo de acordo com as tarefas a serem executadas;

c) A tela, o teclado e o suporte para documentos devem ser colocados de maneira que as distâncias olho-tela, olho teclado e olho-documento sejam aproximadamente iguais;

d) Serem posicionados em superfícies de trabalho com altura ajustável.

A análise identificou que a alínea A está não conforme. O monitor está sem ajuste horizontal e em posicão elevada em relação ao campo de visão do trabalhador. $\mathrm{O}$ mesmo está acima do o ângulo visual desejado, conforme mencionado no item 17.3.2. alínea A e Figura 2 que mostra o padrão recomendado.

A análise identificou que a alínea $\mathrm{B}$ está não conforme. O teclado está com pouca mobilidade e espaço para execução das atividades, conforme mostra a Figura 6B. 
A análise identificou que a alínea $\mathrm{C}$ está não conforme. Não existe suporte para documento, conforme mecionado no item 17.4.2 alínea A e Figura 6A. O teclado e monitor, mostrado na Figura 6B e C, não estão com as distancias ideais conforme padrão recomendado na Figura 2.

A análise identificou que a alínea $\mathrm{D}$ está não conforme. Observa-se que não estão posicionados em superfícies ajustáveis, uma vez que mesa e cadeira não são ajustáveis como mencionado anteriormente e indicado na Figura 6D e E.

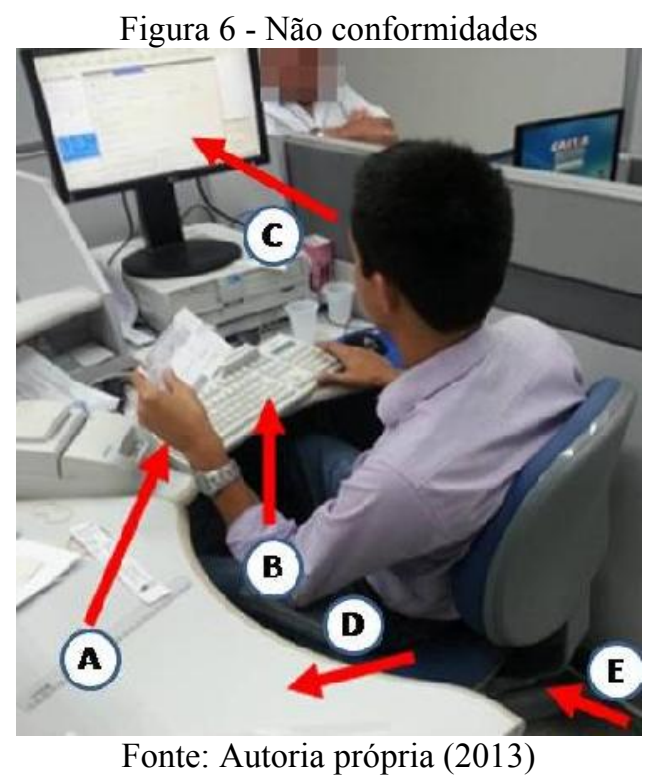

Na sequência, apresenta-se a análise da auditoria com base nos requisitos da norma. Os itens a seguir, referem-se às condições ambientais de trabalho.

Requisito 8: Item 17.5.2. Nos locais de trabalho onde são executadas atividades que exijam solicitação intelectual e atenção constantes, tais como: salas de controle, laboratórios, escritórios, salas de desenvolvimento ou análise de projetos, dentre outros, são recomendadas as seguintes condições de conforto:

a) Níveis de ruído de acordo com o estabelecido na NBR 10152, norma brasileira registrada no INMETRO - Instituto Nacional de Metrologia, Normalização e Qualidade Industrial;

b) Índice de temperatura efetiva entre $20 \mathrm{oC}$ (vinte) e 23oC (vinte e três graus centígrados);

c) Velocidade do ar não superior a $0,75 \mathrm{~m} / \mathrm{s}$;

d) Umidade relativa do ar não inferior a 40 (quarenta) por cento.

A análise identificou que a alínea $\mathrm{A}$ está conforme. O nível de ruído foi medido com um Decibelímetro de referência Minipa MSL 1325, aferido em outubro de 2012 pela empresa Exalta Calibração de Instrumentos de Medidas Técnicas e marcou 58 decibéis, enquadrando-se no limite de 60 decibéis estabelecido pela NBR 10152. 
A análise identificou que a alínea B está conforme. Com o auxílio de um higrômetro de referência Minipa MT-241, aferido em outubro de 2012 pela empresa Exalta Calibração de Instrumentos de Medidas Técnicas foram medidas a temperatura ambiente e umidade. Temperatura ambiente: mínimo $21^{\circ}$ e máximo $23^{\circ}$.

A análise identificou que a alínea $C$ não se aplica.

A análise identificou que a alínea D está conforme. umidade: mínimo 52\% e máximo 58\%. A umidade estava dentro da faixa prescrita pela NR-17 que é umidade relativa do ar não inferior a $40 \%$.

Requisito 9: Item 17.5.2.1. Para as atividades que possuam as características definidas no subitem 17.5.2, mas não apresentam equivalência ou correlação com aquelas relacionadas na NBR 10152, o nível de ruído aceitável para efeito de conforto será de até $65 \mathrm{~dB}$ (A) e a curva de avaliação de ruído (NC) de valor não superior a $60 \mathrm{~dB}$.

A análise identificou que este item está conforme. Após verificação com decibelímetro, mencionado no requisito 8 , alínea A, foi encontrado o valor de 58 decibéis. Portanto, dentro dos limites especificados na NBR10152.

Requisito 10: Item 17.5.3. Em todos os locais de trabalho deve haver iluminação adequada, natural ou artificial, geral ou suplementar, apropriada à natureza da atividade.

A análise identificou que este item está conforme. Existe iluminação no ambiente de trabalho.

Requisito 11: Item 17.5.3.1. A iluminação geral deve ser uniformemente distribuída e difusa.

A análise identificou que este item está conforme. Iluminação distribuída uniformemente.

Requisito 12: Item 17.5.3.2. A iluminação geral ou suplementar deve ser projetada e instalada de forma a evitar ofuscamento, reflexos incômodos, sombras e contrastes excessivos.

A análise identificou que este item está conforme. No posto de trabalho não foram identificadas sombras, reflexos ou contrastes que causem ofuscamento aos trabalhadores.

Requisito 13: Item 17.5.3.3. Os níveis mínimos de iluminamento a serem observados nos locais de trabalho são os valores de iluminâncias estabelecidos na NBR 5413, norma brasileira registrada no INMETRO.

A análise identificou que este item está conforme. Esse item foi medido no ambiente de trabalho dos caixas, com um luxímetro de referência Minipa MLM 1011, aferido em outubro de 2012 pela empresa Exalta Calibração de Instrumentos de Medidas Técnicas, registrando o valor de 636 lux, enquadrando-se na NBR 5413 que indica o valor máximo de 750 lux para atividades de atendimento ao público nos bancos. 
Requisito 14: Item 17.5.3.4. A medição dos níveis de iluminamento previstos no subitem 17.5.3.3 deve ser feita no campo de trabalho onde se realiza a tarefa visual, utilizando-se de luxímetro com fotocélula corrigida para a sensibilidade do olho humano e em função do ângulo de incidência.

A análise identificou que este item está conforme. O nível de iluminação foi medido com luxímetro citado no item anterior, no local onde os operadores de caixa trabalham, e o nível de iluminação ficou dentro do especificado.

$\mathrm{Na}$ sequencia, apresenta-se a análise da auditoria com base nos requisitos da norma. Os itens a seguir referem-se à organização do trabalho.

Requisito 15: Item 17.6.3. Nas atividades que exijam sobrecarga muscular estática ou dinâmica do pescoço, ombros, dorso e membros superiores e inferiores, e a partir da análise ergonômica do trabalho, deve ser observado o seguinte:

a) Todo e qualquer sistema de avaliação de desempenho para efeito de remuneração e vantagens de qualquer espécie deve levar em consideração as repercussões sobre a saúde dos trabalhadores;

b) Devem ser incluídas pausas para descanso;

c) Quando do retorno do trabalho, após qualquer tipo de afastamento igual ou superior a 15 (quinze) dias, a exigência de produção deverá permitir um retorno gradativo aos níveis de produção vigentes na época anterior ao afastamento.

A análise identificou que a alínea A está conforme. Não são realizados avaliações de desempenho individuais para fins de remuneração ou vantagens aos colaboradores.

A análise identificou que a alínea B está não conforme: Não esta sendo realizada a pausa de 10 minutos apos o ciclo de 50 minutos trabalhados.

A análise identificou que a alínea $\mathrm{C}$ está conforme. A gerência do banco cobra gradativamente a produção dos funcionários com problemas de saúde ou que retornaram de afastamento.

Foram realizadas entrevistas informais com gerentes para avaliar e coletar dados desse requisito da norma, visto que essas respostas são de responsabilidade deles.

Requisito 16: Item 17.6.4. Nas atividades de processamento eletrônico de dados, deve-se, salvo o disposto em convenções e acordos coletivos de trabalho, observar o seguinte:

a) $\mathrm{O}$ empregador não deve promover qualquer sistema de avaliação dos trabalhadores envolvidos nas atividades de digitação, baseado no número individual de toques sobre o teclado, inclusive o automatizado, para efeito de remuneração e vantagens de qualquer espécie; 
b) O número máximo de toques reais exigidos pelo empregador não deve ser superior a 8.000 por hora trabalhada, sendo considerado toque real, para efeito desta NR, cada movimento de pressão sobre o teclado;

c) O tempo efetivo de trabalho de entrada de dados não deve exceder o limite máximo de 5 (cinco) horas, sendo que, no período de tempo restante da jornada, o trabalhador poderá exercer outras atividades, observado o disposto no art. 468 da Consolidação das Leis do Trabalho, desde que não exijam movimentos repetitivos, nem esforço visual;

d) Nas atividades de entrada de dados deve haver, no mínimo, uma pausa de 10 minutos para cada 50 minutos trabalhados, não deduzidos da jornada normal de trabalho;

e) Quando do retorno ao trabalho, após qualquer tipo de afastamento igual ou superior a 15 (quinze) dias, a exigência de produção em relação ao número de toques deverá ser iniciado em níveis inferiores do máximo estabelecido na alínea "b" e ser ampliada progressivamente.

A análise identificou que a alínea A está conforme. Não são realizados avaliações de desempenho, conforme mencionado no item 17.6.3 alínea A.

A análise identificou que a alínea B está conforme. Os caixas não são mensurados pela quantidade de toques sobre o teclado, entretanto estão dentro dos limites estabelecidos na norma, realizando aproximadamente 700 toques/hora. Foi verificada a média de valores digitados nas fitas de fechamento dos caixas, documento que contem tudo que foi digitado pelo caixa durante o dia, chegando a esse valor.

A análise identificou que a alínea $C$ está não conforme. Os caixas realizam jornada de 6 horas de trabalho por dia, passando uma hora a mais que o normatizado.

A análise identificou que a alínea D está não conforme: Não esta sendo realizada a pausa de 10 minutos após o ciclo de 50 minutos trabalhados.

A análise identificou que a alínea E está conforme. A gerência do banco exige de forma gradativa a produção do trabalhador que retorna de afastamento por problema de saúde, conforme mencionado no item 17.3.6 alínea C.

Foram realizadas entrevistas informais com gerentes para avaliar e coletar dados desse requisito da norma, visto que essas respostas são de responsabilidade deles.

Após conclusão da auditoria verificou-se que existem não conformidades relacionadas ao não atendimento da NR 17, e também a itens não avaliados pela norma, como por exemplo: posturas inadequadas, como mostra a Figura 1D. Percebe-se que os colaboradores estão adotando posturas incorretas no modo de sentar, no posicionamento da coluna e dos pulsos, várias vezes na realização das atividades. Portanto, trata-se de um erro do próprio funcionário não do ambiente de trabalho em si. Desta forma, falha tem ocorrido por falta de conhecimento técnico das posturas ergonomicamente incorretas ou por força de hábito. 


\section{Resultados}

Diante da auditoria realizada no posto de trabalho dos caixas do banco, diagnosticou-se os pencentuais de conformidades e não conformidades encontradas no setor com base na NR17, conforme apresentados no Quadro 1.

Quadro 1 - Resultado da auditoria NR17

\begin{tabular}{|c|c|c|}
\hline Classificação & Quantidade de Itens & $\%$ \\
\hline Conforme & 19 & $\mathbf{5 7 , 5 8}$ \\
\hline Não Conforme & 14 & 42,42 \\
\hline TOT AL: & 33 & 100 \\
\hline
\end{tabular}

Fonte: Autoria própria (2013)

O resultado apurou um valor significativo de $42,42 \%$ de itens que não estão de acordo com a NR 17 e 57,58\% que estão em conformidade com a mesma.

Sendo assim, é de extrema importância salientar que o não cumprimento da legislação vigente pode gerar sérios prejuízos para a organização. Desta forma, ocasionando penalidades e pagamento de multas em função das irregularidades encontradas no ambiente de trabalho.

Vale ressaltar um exemplo recente, quando a Procuradoria Regional do Trabalho da $11^{\mathrm{a}}$ Região entrou com uma ação civil pública contra a Samsung Eletrônica da Amazônia no valor de R\$ 250 milhões. A ação penalizou a empresa por danos morais coletivos devido as irregularidades identificadas no ambiente de trabalho e por meio de um inquérito promovido pelo Ministério Público do Trabalho (MPT, 2013).

Neste contexto, fica evidenciado que as empresas devem considerar as recomendações da norma, a fim de evitar esse tipo de prejuízo financeiro e ainda assegurar uma boa imagem da organizaçào diante da justiça, dos clientes e dos seus colaboradores.

\section{Considerações finais}

Esta pesquisa partiu das reclamações e queixas dos operadores de caixa de um banco, que alegavam sentir dores nas costas, pernas e membros superiores, em função de prováveis problemas ergonômicos no posto de trabalho, como equipamentos, organização do trabalho, mobiliário e sua disposição inadequada. A partir disso, foi realizada uma auditoria de todos os itens da NR 17, onde foi constatado que 14 não estão conformes a norma recomenda, representando um índice significativo de $42,42 \%$ do total verificado. 
Diante dos dados apresentados verificou-se que as reclamações dos operadores de caixas eram pertinentes, uma vez que foi detectado um valor elevado de não conformidades no ambiente de trabalho, e esses é motivo que têm gerado dores e desconfortos nos caixas durante a realização das atividades. Vale ressaltar, que também foram diagnosticados problemas de posturas incorretas por parte dos funcionários, item nao verificado pela NR 17, não sendo um problema do ambiente de trabalho, e sim do próprio trabalhador.

O diagnóstico da pesquisa contribuiu muito para empresa no sentido de identificar todos os itens que não estão de acordo com a norma regulamentadora. Ficaram evidenciados e mapeados todos os pontos inconformes, facilitando para instituição solucionar os problemas ergonômicos e adequar o posto de trabalho a NR 17, e ainda estabelecer um ambiente mais seguro, confortável e eficiente para seus colaboradores.

Como proposta de trabalhos futuros, pretende-se realizar um plano de ação para corrigir as irregularidades encontradas no setor dos caixas, e ainda promover a sensibilização de treinamentos sobre ergonomia, a fim de conscientizar os colaboradores sobre as posturas corretas, tendo em vista que foram observadas várias posições inadequadas durante a realização das atividades. Após isso, realizar uma nova auditoria para verificar se de fato os problemas ergonômicos foram resolvidos e adequados à NR 17. Outra proposta de trabalho futuro seria estender a pesquisa para outras agências bancárias, a fim de diagnosticar irregularidades em outros bancos.

É de extrema importância que as empresas se adequem às legislações vigentes para evitar penalidades e pagamentode multas, em especial os bancos, onde se concentram um dos maiores números de afastamentos do trabalho pelo INSS, em função de doenças causadas por esforços repetitivos e por irregularidades ergonômicas no ambiente de trabalho.

\begin{abstract}
Faced with several claims and employee complaints about possible ergonomic problems in the workplace of cashiers of a bank, was seen a need to conduct an ergonomic analysis of the workstation, in order to investigate possible irregularities in the sector, based on NR17. Therefore, the research aims to conduct an audit of all items of the NR17 in the section of the cashiers of a bank, and to measure their suitability for this standard. The methodology used was literature, descriptive, field, quantitative and case study, through observations "in loco", informal interviews, and daily monitoring of activities. After audit conclusion it was found that $42,42 \%$ of the evaluated items are not according to the standard orientation.
\end{abstract}

Key-words: ergonomic analysis; working conditions; NR 17; compliance.

\title{
Referências
}

ABERGO. Associação Brasileira de Ergonomia. Ergonomia. Disponível em: <http://www.abergo.org.br >. Acesso em: 17 de julho de 2013.

BATALHA, O. M. Introdução à engenharia de produção. Rio de Janeiro: Elsevier, 2008. 312p. 
BRASIL, .Ministério do Trabalho e Emprego. Manual de aplicação da norma Ergonomia. Editora Blucher, 2007.

FALZON, P. Natureza, objetivos e conhecimentos da ergonomia, in FALZON, P.

GUERIN et al. Compreender o trabalho para transformá-lo. Tradução Giliane M. J. Ingratta, Marcos Maffei. -São Paulo, Edgard Blücher, Fundação Vanzolini, 2004.

GUÉRIN, F.; LAVILLE, A.; DANIELLOU, F.; DURAFFOURG, J. \& KERGUELEN, A. Compreender o trabalho para transformá-lo: A prática da Ergonomia. São Paulo: Edgard Blücher: Fundação Vanzolini, 2001.

IIDA, I. Ergonomia: Projeto e Produção. 2. ed. São Paulo: Edgard Blucher, 2005.

MÁSCULO, F. S.; VIDAL, M. C. (orgs.). Ergonomia: trabalho adequado e eficiente. Rio de Janeiro, Elsevier/ABEPRO, 2011.

MINISTÉRIO DO TRABALHO E EMPREGO. Norma Regulamentadora - Disposições Gerais Portaria $\mathrm{n}^{\circ} 3.751$, 1990. Disponível em: <http://www.mte.gov.br/legislacao/normas_regulamentadoras/nr_01.asp>. Acesso em: 10 de jun. 2013.

MINISTÉRIO DO TRABALHO E EMPREGO. Norma Regulamentadora - Ergonomia; Portaria $\mathrm{n}^{\circ} 3.751,1990$. Disponível em $<$ http://www.mte.gov.br/legislacao/normas_regulamentadoras/nr_17.asp $>$. Acesso em: $10 \mathrm{de}$ jun. de 2013.

MINISTÉRIO DO TRABALHO E EMPREGO. Manual de aplicação da Norma Regulamentadora $\mathbf{n}^{\circ} \mathbf{0 1} .2^{\circ}$ Ed. Brasília, 2002. Disponível em: <www.mte.gov.br/seg_sau/pub_cne_manual_nr17.pdf>. Acesso em: 05 jun. de 2013.

MUNDO ERGONOMIA. Disponível em: <http://www.mundoergonomia.com.br>. Acesso em: 02 jul. 2013.

MINISTÉRIO PÚBLICO DO TRABALHO (MPT). Disponível em:

$<$ http://www.tribunahoje.com/noticia/72354/economia>. Acesso em: 13 de ago. 2013.

NR 17 - Norma Regulamentadora sobre Ergonomia, estabelecida por meio da Portaria $n^{\circ} 3.751$, de 23 de novembro de 1990, do então Ministério do Trabalho e Previdência Social.

NR 1 - Norma Regulamentadora. Disposições Gerais, estabelecida por meio da Portaria n ${ }^{\circ} 3.214$, de 23 de junho de 1978, do então Ministério do Trabalho e Previdência Social.

PERES, L. País gasta R\$ 981 milhões com LER em bancários. São Paulo: Folha de S.Paulo.2009. Disponível em: $<$ http://www1.folha.uol.com.br/fsp/dinheiro/fi2904200714.htm). Acesso em: 15 de jul. 2013 regulamentadora n.17. 2. ed. Brasília: MTE/SIR, 2002.

SERVIÇOS ESPECIALIZADOS DE FISIOTERAPIA - SEFIT. Disponível em $<\mathrm{http}$ ://www.sefit.com.br/sala-deimprensa/ergonomia-nas-empresas-e-lei>. Acesso em: 05 de jun. 2013.

\section{Dados dos autores}

\section{Nome completo: Fábio Xavier de Oliveira}

Filiação institucional: Universidade Federal do Amazonas - Faculdade de Tecnologia

Função ou cargo ocupado: Aluno da graduação finalista do Curso de Engenharia da Produção

Endereço completo para correspondência (bairro, cidade, estado, país e CEP): Travessa Rosa de

Maio, $n^{\circ}$ 10, Bairro Colônia Santo Antonio, CEP 69093-352

Telefones para contato: 092-81375980

e-mail: fabio_xav@hotmail.com

Nome completo: Marcelo Augusto Oliveira da Justa 
Filiação institucional: Universidade Federal do Amazonas - Faculdade de Tecnologia

Função ou cargo ocupado: Professor Mestre do Curso de Engenharia da Produção

Endereço completo para correspondência (bairro, cidade, estado, país e CEP): Rua 30, $\mathrm{n}^{\mathrm{o}}$ 19,

Quadra A-37, Conj. Jd Versalles, Bairro Planalto, CEP 69044-770

Telefones para contato: 092-91258387 ou 81792273

e-mail:marcelo.justa@bol.com.br

Submetido em: 21/02/2014

Aceito em: 22/10/2014 